\title{
Former President Chun-chieh Huang Received Awards for Teaching Excellence
}

Professor Chun-chieh Huang 黄俊傑, University Chair Professor and Dean of the Institute for Advanced Studies in Humanities and Social Science, National Taiwan University, has had the honor as a National Chair Professor since 2013, which is the most prestigious title for professors in Taiwan.

In 2011, Professor Huang received the Ministry of Education Academic Award and the National Award for Teaching Excellence in General Education. He also received the Award for Life-long Contribution to General Education from the Chinese Association for General Education in the same year.

In 2014, Professor Huang was the recipient of the Jiang Pingkun Academic Award for Cross-strait Exchange.

Professor Huang is the Second President of the Society.
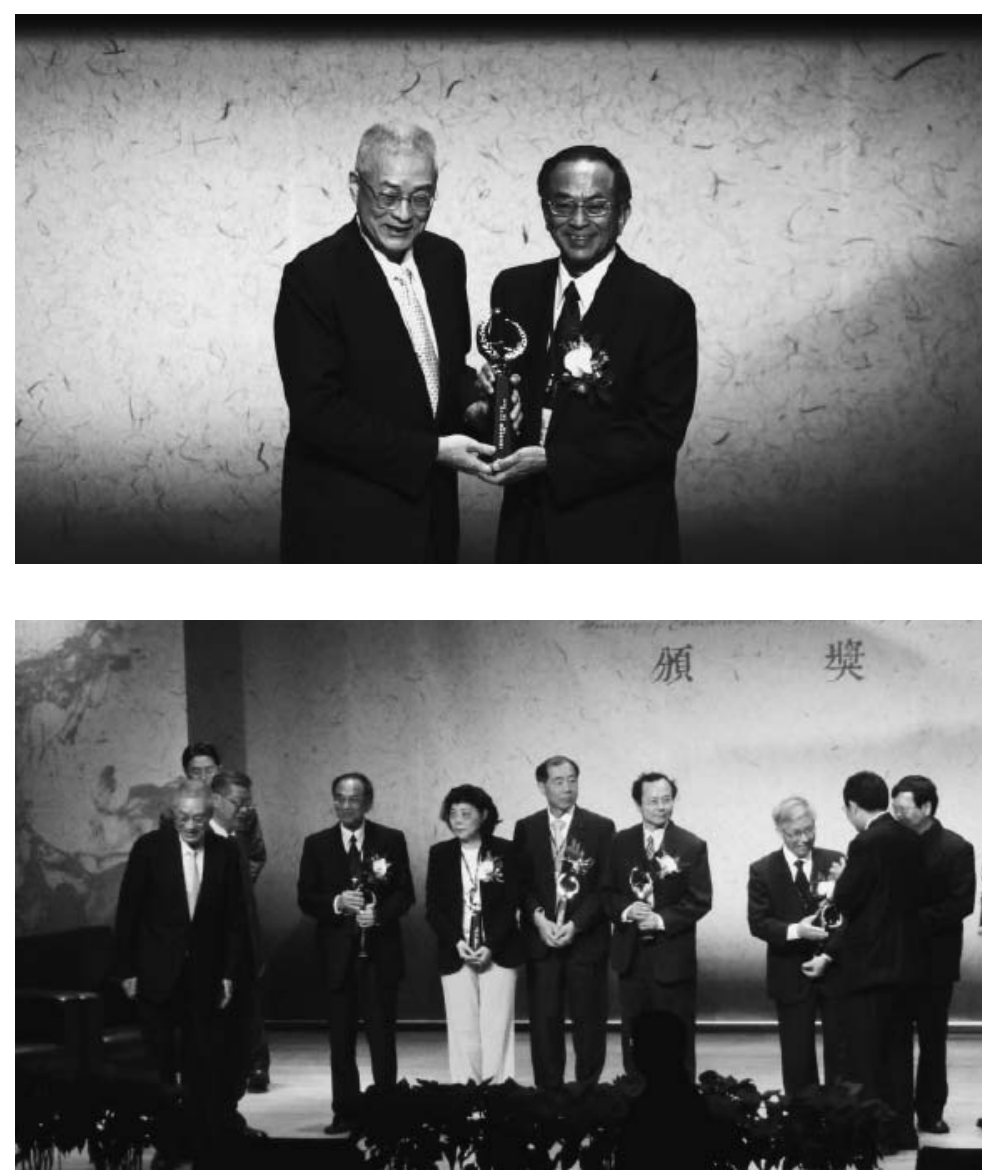

Courtesy of IHS, NTU 